\section{RAMAKIAN IN MODERN PERFORMANCE: A WAY TO COPE WITH A CULTURAL CRISIS ${ }^{*}$}

\section{Kittisak Kerdarunsuksri ${ }^{* *}$}

\begin{abstract}
In the Bangkok period, the literary classic Ramakian has been reproduced again and again, either in literary forms or performing arts. This literary piece has been reinvented many times, particularly in the course of cultural crisis so as to demonstrate the glory of Thai culture. Although Ramakian is still able to be seen in the form of traditional theatre, i.e., khon (a masked dancedrama) in particular, it was also re-created in modern theatrical form during the mid-1990s, during which a cultural campaign was promoted by the government. This paper focuses on three modern theatrical productions of Ramakian: Rama - Sida (1996), Nonthuk (1997), and Sahatsadecha (1997), The paper addresses the questions: why was this classic re-created in modern performance and how was the story revised to make it fit into today's society.
\end{abstract}

* This is a revised and expanded version of a paper entitled Ramakian in Modern Performance: The Reflection of an Identity Crisis presented in the 7 th International Conference on Thai Studies, 4-8 July 1999, Amsterdam, The Netherlands.

" Lecturer at the Department of Thai Language for Communication, The University of the Thai Chamber of Commerce.

\section{Introduction}

Since the very beginning of the Bangkok period, whenever the ruling elite was acutely aware of a cultural crisis inside its community, the so-called 'national cultural heritage' (mo'radok thang watthanatham kho'ng chat), i.e, art and tradition, was usually exploited to carry out the task of tackling this difficult situation. Such cultural patrimony was normally picked up from the court resource, e.g, literature, performance, ceremony, and so forth. Inevitably, the saga of 'Rama' or Ramakian, which was inseparably associated with the ruling class and the polity, has usually been reproduced for the purpose of exhibiting national cultural heritage. As the repertoire of traditional kinds of performance, such as khon and nang yai (a large shadow puppet), the reinvention of Ramakian then was an imposing means for the Thai ruling group to proclaim the greatness of national culture through literature and performance.

During the influx of Western culture, and up to the present day, Ramakian has continued to be reworked in the performing arts. Interestingly, not only has this classical literary piece been found in traditional theatre, but it has also been reinvented in modern performance form during the Years of Thai Cultural Preservation or pi ronnarong watthanatham thai (1994-97). It is therefore the purpose of this paper to study the reinvention of this classic in modern performance to illustrate the crisis of cultural identity in today's society: why was Ramakian re-created in modern theatrical form during the official campaign of cultural promotion and to what extent was the meaning of this saga adapted to be suitable for 
modern society. The paper focuses on three modern theatrical productions, namely, Mattani Rutnin's Rama - Sida (1996), Pornrat Damrhung's Nonthuk (1997), and Phatravadi Mejudhon's Sahatsadecha (1997). To demonstrate the significance of Ramakian as an instrument for dealing with cultural crisis in Thai society, the paper first describes the historical background regarding the purpose of re-creating this literary work in the Bangkok period. It then discusses the current cultural crisis and the reproduction of Ramakian in the 1990s. The materials used in the study of Rama - Sida and Sahatsadecha are based on its unpublished script and videotape. As for Nonthuk, only the videotape is analyzed because the production, as a movement performance, has no written script.

\section{Background of the Reinvention of Ramakian}

In the reign of King Rama I, the king commissioned the court poets to compose the whole story of Ramakian, which is the only complete version in Thailand. His effort in completing the full story of Ramakian was not only to reconstruct the text, which was believed to have disappeared during the sacking of Ayutthaya, but also to set a new standard for his own reign and the new dynasty. The king attempted to establish new ideas and ideologies under the old tradition. By then, it can be said that the Thai ruling group, whose who had been involved with power in the royal court of Ayutthaya, encountered a cultural crisis as a result of the defeat in the war against the Burmese. They realized not merely the material loss but also the ineffectiveness of their socio-political system and traditional values (Nithi 1995: 4). On his accession to the throne, King
Rama I felt the need to make sense of the kingdom's calamity. He was expected to be, to some extent, a 'better' king than his predecessors, at least in normal terms. In other words, he needed to conduct effective administration, social welfare, or else, of the secular world and establish moral order. The return to Ayutthaya therefore was not a simple task for him. In turn, he established an absolutely new relationship between monarchy and society founded upon rational communication (Wyatt 1996: 162-172). As stated in the epilogue of his royal Ramakian, this work was merely nonsense fiction of which the readers should not be obsessed. (King Rama I, vol. 11, 1964: 307)

Nevertheless, it is evident that the king aimed at employing the story as a tool to legitimize his power, since he named his dynasty 'Chakri'. Undoubtedly, this name is the equivalent of God Vishnu and his weapon. The king's status was thus comparable to a god; he was a divine-king who was reincarnated to alleviate the people's suffering. The setting in his Ramakian, which was elaborately described, was the newly constructed capital, Bangkok. The description of glittery decoration of new buildings showed his determination that the glory of Bangkok should measure up to that of Ayutthaya.

Under the threat of Western imperialism in the nineteenth century, the Thai ruling elite faced a crisis of cultural identity again. To maintain Siamese sovereignty was to modernize and westernize the country. The Thai elite needed to adjust themselves to Western culture, i.e., in education, dress, etiquette, and lifestyles, yet realize their identity and their cultural roots. Their ultimate goal was to maintain their power and 
sovereignty. Accordingly, the Thai ruling class continued to maintained the traditions they deemed necessary in exhibiting the prestige and dignity of Siam and practical in paving the way for the country's modernization. The process of modernization can be seen from King Mongkut's reign onwards.

One of King Mongkut's policies to promote the notion of a glorious country was to revive the court performance of Ramakian, which had been banned during the previous reign. ${ }^{1}$ In doing this, he deliberately selected certain episodes for recomposition for the repertoires of his royal troupe. The episodes chosen reflected his subtle intention to communicate with his audience, not only his people but also his foreign royal guests. $\mathrm{He}$, for example, rewrote the episode of Phra Ram Doen Dong (Rama Wandering in the Forest). This episode noticeably echoed his own renunciation of his right to the throne and his retirement from worldly pleasure to enter an ecclesiastical life in order to make way for the crowning of his half brother, King Rama III. He also recomposed the episode of Narai Prap Nonthuk (God Vishnu Defeating Nonthuk the Demon) as a separate prelude performance or bot boek rong. It is plausible that his intention in producing this episode as a short prelude was to modernize tradi-

${ }^{1}$ As a pious king, King Rama III considered dance-drama wasteful luxury. His displeasure with dance-drama may have resulted from the irregular behaviour and way of life of some dance-drama people, probably those outside his court. For example, the scandal of Prince Rakronnaret involving his affairs with his dancers was said to cause mistakes in his official responsibilities. Furthermore, the prince plotted to usurp the throne. King Rama III then took away his royal title, and eventually executed him. See Mattani Rutnin 1993: 60-61. tional performing arts to attract his audience, foreigners who were not familiar with a long, slow-pace performance of traditional kind in particular. The story of this episode, which is the origin of the Thai saga of Rama, by implication, also mirrored the fact that it was he who was reincarnated to fight evil, i.e., the threat of the West, and to bring peace to his citizenry.

According to Nithi (1995: 16-21), it is likely that the crux of the crisis of cultural identity among the Thai elite during the colonialism period took place in King Vajiravudh's reign. It seems that a sense of cultural inferiority was apparent in his court since the elite, from the king down to high-ranking officials, adhered to Western culture as a model. This resulted from the fact that they were educated abroad. Yet under his nationalist ideology, King Vajiravudh also sought to preserve Thai culture. Even though the standards of the modern world were based on Western values, Siam needed to be proud of her own culture as well. For him, the reemphasizing and reinforcing of the significance of the past seemed essential to promote his nationalist programme (Vella 1978: 202-242).

King Vajiravudh made use of traditional elements through religion, history, literature, and theatre. Again, Ramakian was chosen to present a cultural identity despite the fact that his works on Ramakian were based on the English translation of the Sanskrit version. (See the preface in King Vajiravudh, 1959) To demonstrate civilized nationhood, he further investigated the origins of Ramakian by composing the valuable source, Bo' Koet haeng Ramakian (The Origins of Ramakian), for literary study. (See also the preface of this book in King 
Vajiravudh, 1960)

\section{Today's Cultural Crisis and its Resolution}

It has been said that today's cultural crisis results from the social changes to which most Thais are not able to adapt themselves and with which they are unable to cope. (See Ekkawit, 1989) Amidst the overwhelming inflow of external culture, especially Western ${ }^{2}$, and due to economic development over the past four decades, Thai society has rapidly and dramatically changed in every aspect, including the Thai lifestyles. The advent of a new economic system and new technologies disrupts the traditional values and lifestyles. Even though they have characterized the modernity and variety in Thai society on the one hand, at the same time society has encountered conflict and problems on the other. While the development of the country towards a newly industrialized country (NICS) once became a new image of the country that successive governments sought to promote through the mass media, affluence and social welfare have not been distributed thoroughly and equally. Moreover, the demands for modern conveniences for better and more comfortable living have tempted both rural and urban people go to any lengths, even getting into debt or wrongdoing, such as robbery and drug trade, in order to acquire what they need. The crisis of cultural identity confronting Thai society today is therefore a consequence of adopting an external culture - capi-

\footnotetext{
2 The term 'Western culture' may now include Japanese and advanced technologies. See Sulak Sivaraksa's speech on the identity crisis in Thailand in Reynolds 1993: 4157.
}

talist culture - without careful and shrewd selection. It can be said that the cultural crisis has been recognized by the disruption of the traditional moral code and the disregard for folk wisdom.

Successive Thai governments realized the effect of social changes on cultural identity. In 1993, the government thus designated the year 1994 as the official year to promote a cultural campaign under the name "Year of Thai Cultural Preservation" and later extended the campaign to $1997 .{ }^{3}$ Indeed, the issue of national and cultural identities was raised on the World stage during the last two decades, particularly when discussing the social changes as well as the economic development of Third world countries. The recommendation to 'foster cultural identity', i.e., the preservation, strengthening and development of cultural identity, has become important objectives of UNESCO statements on cultural programmes (Bechstedt 1993: 293). The designation of the cultural promotion years of the Thai government was then a response to an agreement of the world organization, the United Nations and its suborganizations, in promoting the use of the cultural dimension for development.

As stated in the booklet entitled Kan Ronnarong Watthanatham Thai pho' so' 2537-2540 (The Campaign for Thai

\footnotetext{
${ }^{3}$ The extension of this cultural campaign was under the project of 'Carrying on Thai Cultural Works' (Khrongkan Su'psan Ngan Watthanatham Thai). Over a period of four years (1994-97) each emphasized the use of Thai culture in different ways: culture and education (1994), culture and development (1995), culture and tourism (1996) and culture and mass media (1997).
} 
Culture 1994-97) published by the Office of the National Culture Commission, the main objective in the designation of this official period was to encourage all Thais to learn, appreciate, and maintain so-called 'good Thai culture' (watthanatham an di ngam kho'ng thai). In addition, the government needed to idealistically make use of this campaign to solve social and cultural problems. The framework of this cultural campaign includes: the institutions of nation, religion, and monarch; family and community; convention and tradition; language; order and discipline; value, virtue, and morals; way of life and folk wisdom; costume; arts; culture and tourism; and culture and development. It is obvious that the cultural campaign was not only to promote traditional 'things' so as to show the national and cultural identity, but also to use cultural 'things' for the benefit of economic development.

It is apparent that, during the years officially promoting Thai culture a number of classical literary works were performed on stage. It is no exaggeration to say that the adaptation of classical literature became a popular trend in Thai theatrical circles over this period. (See Kittisak 2001: 7) It would not be surprising if these classics had been reworked in the form of traditional theatre since several pieces have formed the repertoires of traditional theatrical genres. However, these literary pieces turned out to be re-created in modern theatrical form, specifically during the course of the government's campaign of Thai culture. Did the government encourage the trend of such adaptation? To what extent and how did the Years of Thai Cultural Preservation play a role in generating this trend? These questions likely lead to considering the relation between the reproduction of literary classics, including the Ramakian, and the reflection of the crisis of cultural identity in a modern Thai social context.

\section{The Reproduction of Classical Literature in Modern Theatre in Thailand in the 1990s}

Under the campaign to promote language and literature, the Office of National Culture Commission organized the 'Khrongkan Sisan Wannakam' (Colour of Literature Project) to present Thai literature through various sorts of performance in the hope that Thai youth would realize the value of Thai language and literature. The performing arts were used as a tool to teach literature more enjoyably. Interestingly, modern theatre, which is a directly imported genre, was chosen to be the means of conveying culture at university level, whereas traditional forms were used at lower educational levels. This means that a modern genre is allegedly more suitable for imparting new ideas or reinterpreting 'old' literary works within a new social context.

One may question why traditional theatre is deemed unsuitable for presenting new viewpoints. This is likely due to the perception of traditional theatrical aesthetics, in which the audience delights in the 'beauty' of the dance movement, costume, music, and so on, rather than paying attention to the presentation of ideas. Apart from this, the presentation of classical literature in traditional forms seems to carry the advantage of transmitting cultural 'things', whether literary or theatrical. Traditional forms are thus suitable for junior youth in order to instil in them a feeling of love for national art and culture. 
In fact, the transformation of classical works into modern theatre in the $1990 \mathrm{~s}$ had existed prior to the Colour of Literature Project. ${ }^{4}$ Shortly before this project, for instance, Phatravadi Mejudhon, a legendary actress in the Western style, had turned her interest to her Thai roots after having staged or adapted many Western plays for production. In this regard, she claims that she has never appreciatively understood Western philosophy in the plays, despite having graduated from abroad and having remained a long time there (Personal interview, 3 June 1998). When she founded her own open-air theatre in 1992, she then made use of traditional stories, both folk and classical, as a source for her productions to communicate with the Thai audience. ${ }^{5}$ Staging original Thai stories is perhaps more understandable to and appreciated by the audience. Moreover, the demand for original modern Thai scripts of as high a standard as that of the West has been rekindled and has become a discourse in Thai theatrical circles from time to time. (See Kittisak 2002: 51) This, coupled with the official current of preserving Thai culture, likely entailed a boom age for the adaptation of classical literature into modern theatre. The Years of Thai Cultural Preservation thus can be said to have been a channel for such a trend in Thai theatre during the 1990s.

\footnotetext{
${ }^{4}$ Before the 1990 s, a few attempts to adapt traditional literary works into modern theatre can also be found, such as the productions of Nai Aphaimani (1971), Rak thi To'ng Montra (1977), Lo'dilokrat(1986), and Phra Sang - Iphigenia (1985). See more details in Kittisak 2001:80-121.

${ }^{5}$ Nithan Khang Wat adapted from Suntho'n Phu's Singhakraiphop was the first production at the Phatravadi theatre.
}

\section{Ramakian in Modern Thai Theatre}

When Mattani ${ }^{6}$, Pornrat ${ }^{7}$ and Phatravadi put Ramakian on stage in the $1990 \mathrm{~s}$, the 'old' content was adjusted to fit into a new social context. While the Ramakian preserved the status of a divine king under the ancien regime, these two theatre practitioners reinterpreted the story by expressing new viewpoints. Even though the original theme of the story, i.e., good defeats evil, was maintained in Rama - Sida, Nonthuk, and Sahatsadecha, Mattani, Pornrat, and Phatravadi sought to draw the story close to the modern audience. Portraying characters as humans seems necessary since the image of divinity no longer sounds sensible in terms of belief. ${ }^{8}$ The following section will discuss each modern theatrical production of Ramakian.

\footnotetext{
${ }^{6}$ Professor of drama at Thammasat University.

7 Associate professor of drama at Chulalongkorn University.

${ }^{8}$ After the 1932 revolution, there were viewpoints against Ramakian. Luang Vichit, for example, condemned this court literature for providing the people with misguided values, erroneous beliefs and wrong role models. In his view, the hero, Phra Ram or Rama, became a weak and cowardly leader who defeated his enemy without doing much. The story of Rama then portrayed an appropriate concept of leadership (see Chapter 1 in Luang Vichitr Vadakarn, 1970). Besides, other movements on the Thai literary scene also generated criticism of this literary work, particularly by the movement of literature for life (wannakam phu'a chiwit). According to Inthrayut (1975: 59), Ramakian was composed to exalt the virtue of kingship; it, in turn, degraded the people as inferiors. It, as he argues, infused the people's mind with the feeling of slavery.
} 


\section{Rama - Sida}

The production of Rama - Sida was organized by Thammasat University in collaboration with the Office of the National Culture Commission in order to celebrate the king's golden jubilee of his ascension to the throne. It was staged at the Thailand Cultural Centre in November 1996. Mattani adapted the script by adapting from King Rama I's Ramakian and directed the production herself. As for its synopsis, it is helpful to relate it in sequence.

\section{Sequence 1}

Music, lighting and the dance movement of devils introduce the atmosphere of evil. Shiva commands Vishnu and Lakshmi to be reincarnated as Rama and Sida in the human world. Meanwhile, Uma orders Maya (lit. illusion) to follow Rama and Sida so as to prove whether good will overcome evil in the globalized age.

Sequence 2

Montho gives birth to Sida. As the baby cries out a word of bad omen, her father, Thotsakan (Ravana), asks his astrologers to predict the baby's fate. Eventually, the baby is marooned in the river.

Sequence 3

Chanok, the hermit, saves the baby and asks the Goddess of Earth to look after her. After sixteen years pass, Chanok takes Sida back and brings her to his city where he becomes king.

\section{Sequence 4}

Chanok organizes the rite of finding a mate for Sida. When Rama meets Sida, they both fall in love at first sight. At the rite, Rama can raise the sacred bow, which allows him to marry Sida.

Sequence 5

Rama's father, Thotsarot, decides to retire from his throne; Rama is then crowned king. Maya manages to tempt Kaiyakesi, one of Thotsarot's consorts, to claim the right to succeed the throne for her son, Phrot, as she once saved Thotsarot's life. Due to the promise that Thotsarot gave to Kaiyakesi to ask for anything she wants, Thotsarot has to give the throne to Phrot instead, while Rama, Sida and Lakshman will live as recluses in the forest for fourteen years. This makes Thotsarot die of grief. Phrot does not consent to what Kaiyakesi has done. He decides to return the throne to his half brother. Yet Rama needs to keep his word by spending his life in an ecclesiastical way; he thus gives his shoes to Phrot as his representative.

Sequence 6

Sammanakkha, Thotsakan's widowed sister wanders in the forest to search for her partner. As she sees Rama's beauty, she desires to marry him. However, when she realizes that Rama has Sida as his wife, she tries to attack Sida. She is finally repelled by Lakshman, who cuts off her nose, ears, hands, and feet. Sequence 7

With her vengeance, Sammanakkha tells his brother about Sida's beauty, which makes Thotsakan have a strong desire for Sida. Though Montho reminds him that Rama is Vishnu's reincarnation, Thotsakan does not seem to pay attention to this.

Sequence 8

Thotsakan orders Marit to transform into a golden deer so as to entice Rama and Lakshman out of their shelter, while Thotsakan disguises himself as a hermit and kidnaps Sida to his city.

Sequence 9

While taking Sida away, Thotsakan is hampered by Sadayu, the great bird, yet he manages to harm the bird. Sadayu, before dying, tells Rama about Sida's abduction. As Rama follows after Sida in the forest, Hanuman and other mon- 
keys offer to serve Rama as his soldiers.

Sequence 10

In Lo'nkka, Hanuman saves Sida who seeks to hang herself. Hanuman offers to bring her back to Rama, but she refuses since she wants Rama to take her back himself.

\section{Sequence 11}

Hanuman fights with Kumphakan, one of Thotsakan's brothers, in battle. Kumphakan eventually dies by Rama's weapon.

Sequence 12

Intho'rachit, Thotsakan's son, volunteers to fight in the war with Rama's army. $\mathrm{He}$ transforms himself to take on the appearance of God Indra. However, he is killed by Lakshman.

Sequence 13

Thotsakan fights in the war himself. Although his head, arms and legs are cut by Rama, it turns out that his body is joined again since he detaches his heart and lets a hermit keep it for him.

Sequence 14

Hanuman plots to steal Thotsakan's heart from the hermit. He and Onkkhot then pretend that they have been expelled from Rama's troop and request the hermit to take them to Thotsakan as they offer to become the demon's soldiers. Finally, they succeed in getting Thotsakan's heart.

Sequence 15

Hanuman and Thotsakan lead the troop to the battlefield. Hanuman shows the heart to the demon who tries to appeal to Hanuman to return it to him. Yet his request is in vain; he is eventually killed by Rama.

Sequence 16

Rama returns to his throne in Ayodhya. In the palace, Maya manages to stir up distrust of Sida's purity among attendants. For this reason, Sida proves herself by walking through fire.
Sequence 17

Maya, in the disguised form of Nang Adun the devil, tempts Sida to draw Thotsakan's portrait, which causes Rama to get angry. He believes that Sida was unfaithful to him. Despite her pregnancy, Rama orders her execution. However, Lakshman, who trusts Sida's purity, sets her free in the forest. After Sida is taken away, Rama repents of his wrong decision.

Sequence 18

In the forest, Rama meets a boy called Mongkut who has mighty power. While Rama is beating Mongkut, Sida comes out. Rama then realizes that Mongkut is his son. No matter how Rama begs for her forgiveness, Sida insists that she will stay in the forest. However, she allows Rama to take Mongkut back to Ayodhya.

Sequence 19

Hanuman informs Sida about Rama's death, so that she returns to Ayodhya. After realizing the trick, Sida prays to the Goddess of Earth to receive her into the earth. Rama is thus in anguish; he promises to rule his kingdom with morality.

Sequence 20

By request of Lakshmi, Sida forgives her husband and returns to Ayodhya. At the end, Uma commands Maya to return to her so that Rama and Sida can prove their true and faithful love to her.

In rewriting Ramakian, Mattani explained the story from her viewpoint. She directly pointed out that the conflicts in the story result from human's intrinsic nature, that is, lust and passion. In so doing, she created a new character, Maya, to symbolize wickedness or the evil instinct of human nature. It can be said that this character enables the theme about good and evil to be comprehended more concretely. Almost every single 
event in the story of Rama - Sida appears to be a consequence of the persuasion of Maya whom Uma, God Shiva's consort, sent to bring about destruction in the human world and to prove whether good would be able to defeat evil in today's world. Kaiyakesi in his desire to seize the right for the throne, for example, is tempted by Maya:

Thotsarot:

I will pronounce that from now on Rama will reign instead of me. It is time for me to retire from the world and search for tranquillity in the forest. Long live King Rama, the virtuous king who assures peace in the kingdom of Ayodhya.

-Rama enters; Thotsarot crowns him. The cheers of the officials become loud.

- Maya enters and then whispers to Kaiyakesi.

Maya:

Will you allow Rama to become king? Actually, it is your son, Phrot, who deserves the throne because you once saved Thotsarot's life.

Kaiyakesi:

(thinking) You remind me of that incident in which the wheel of Thotsarot's chariot broke in the battlefield. I used my arms to brake the wheel, which enabled him to win the fight over the enemy. He then promised to give me whatever I would request.

Maya:

And now, here is the time to ask him to honor his promise. Send Rama to wander in the forest for fourteen years and cede the throne to Phrot.

(Rama-Sida: p. 19)
Also, the characters' desire was driven by Maya's action, for example, in Thotsakan's desire for Sida and Sida's fascination of golden deer. In the performance, Maya, the golden deer and Nang Adun the devil were portrayed by the same actress. This obviously underlines the theme in such a way that the writer-director's retelling the main theme in the original text is straightforwardly found. Moreover, this theme can be related to the cultural crisis in real society, as seen from Uma's dialogue:

Uma:

In the globalized age, evil will win. Although Rama is Thotsarot's son, he will be sent into exile for fourteen years to prove his virtue. Sida must suffer terribly because of her love for Rama.

(Rama-Sida: p. 3)

The dialogue above reflects Mattani's attempt to raise a question on the issue of morality in today's society, since people are easily tempted by lust and passion, which appear in various forms. She, however, points out at the end of the story that love and virtue will help to suppress wickedness as Rama and Sida manage to prove to Uma:

Uma:

I hereby command Maya to return to my heart and go out due to the great love of Rama and Sida, which will protect the world and save people from evil and sins.

(Rama - Sida: p. 70)

The reincarnation of both Rama and Sida is therefore to show that the dhamma will triumph over evil, and that their love is idealistically greater than anything else 
and will support the existence of the world.

Unlike the god-king in Ramakian, Rama in Mattani's Rama - Sida is portrayed as a human whose nature and behaviour are also tempted by Maya. Even though Rama tries to practise being a virtuous king, a flaw in his behaviour is also found. By Maya's incitement, it turns out that Rama seems not to trust his consort's purity after getting her back from Thotsakan. Finally, he realizes his mistakes and he laments:

Rama:

Alas! Our love and promise are gone by Maya. Oh! Shiva and Uma, please forgive what I did to Sida. I swear to the earth and sky that I will eternally rule my kingdom and people with the ten virtues of a king.

(Rama - Sida: p. 65)

In addition to the main theme, Mattani also kept the concept of loyalty, which in Ramakian was usually used to support the status of divine-kingship. Since the performance of Rama - Sida was produced on the occasion of the celebration of King Bhumibhol's golden jubilee, maintaining the notion of loyalty in this production, by implication, was the writer-director's intention to honour the king. In Rama - Sida, the loyalties of Sida, Lakshman, Phrot and Rama's monkey soldiers, particularly Hanuman, to Rama were clearly demonstrated. In the scene of finding a bridegroom for Sida, for example, Rama allows Lakshman to raise the bow first; however, Lakshman realizes that his brother is falling in love with Sida, he then pretends that he cannot raise it:
Singer:

When reaching, he [Lakshman] grasps Shiva's bow. As it is moving, he realizes that he can raise it.

- Lakshman puts the bow down. Rama is looking at Lakshman and he understands that his brother tries not to raise the bow.

Maya:

Lakshman, you are as powerful as your brother, Rama. So you should raise the bow with your mighty power in order to get Sida. You wish to marry her, don't you?

- Lakshman remains still for a moment and then shouts to Maya.

Lakshman:

Maya, the devil! Do not tempt me. I promised to Rama that I will offer him my loyalty and gratitude. Get out!

$$
\text { (Rama - Sida: p. 18) }
$$

Also, in the war between Rama and Thotsakan, Hanuman proves that he remains on Rama's side, even if he becomes Thotsakan's adopted son:

Thotsakan:

(surprised) Oh! That is the box which contains my heart. Please give it to me, my son.

- Hanuman hesitates. Rama is not certain whether Hanuman remains on his side or not, and thus prays.

Rama: Let the virtue of the god make Hanuman remain loyal to me.

- There is a halo around Rama. Hanuman prostrates himself before Rama, then points towards Thotsakan. 
Hanuman:

Alas! Thotsakan, you fool! You think that you can "buy" [sic] my heart, don't you? You are so wicked that you and all your family deserve death.

$$
\text { (Rama-Sida: p. 44) }
$$

Due to her interest in feminist issues, furthermore, Mattani also sought to promote feminist ideas in this production through Sida's dialogues and actions.? At the rite of walking through fire in honour of her husband's dignity, she laments:

Sida:

Throughout the anguished fourteen years, it is regrettable that my husband does not trust me. Why do I have to live in shame? Born as a woman, I have to suffer from such a man.

(Rama-Sida: p. 45)

Sida, moreover, laments her gender, as her husband demands her execution when he finds her drawn of Thotsakan. With her resentment, she expresses herself to Lakshman:

Sida:

I was born as a woman, I have no rights in my life. I am very sad at my fate, that I have to die because of a sin I have never committed. For my next life, I pray that I would not be born as a woman anymore.

$$
\text { (Rama - Sida: p. 53) }
$$

However, Sida's suffering in her fate is

\footnotetext{
${ }^{9}$ It is evident that Mattani is interested in feminist issues, as seen from her scholarly and theatrical works. For example, she wrote about the role of women in the modernization of traditional dance-drama in the reign of King Chulalongkorn (see Mattani 1996a:
}

given a reason, as Lakshmi says, that she was born to fulfil the great work of a god, that is, salvation. She then needs to be patient, as do all women in the world. This clearly reflects Mattani's attitude towards the female gender. Even though she tries to present her feminist ideas through the characterization of Sida, she also draws the important role of the male in pointing out that both male and female are mutually dependent components of nature, as in the line of Uma:

Uma:

Now I realize the faithfulness and loyalty of him [Rama] who is the god of the family and woman. Please return to the arms of Rama who is your husband and the father of all human beings.

$$
\text { (Rama-Sida: p. 68) }
$$

It is clear that Mattani's notion about the feminist issue is not as forceful as that of the West. Rather, her feminist idea deals with making a compromise between the status of men and women as a result of an awareness of the social inequity Sida experiences.

As for the theatrical form of this production, Mattani made use of both Thai and Western theatrical styles. Traditional Thai dance form, Hon in particular, is discernible. The traditional dance posture of khu'n loy, a characteristic of fighting scenes in which a dancer stands upon another dancer in khon per-

147-150). Additionally, in her production of Butsaba-Unakan she also adapted the literary classic, Inao, to address the heroine's fate by raising the question whether women in ancient society have any right and are at liberty to carry out their own free will (see Kittisak 2001: 180-189). 
formance, remains in the fighting scenes of this production to reveal the original roots of Ramakian in Thai theatre. At the same time, Western dance styles are used for the movements of Maya and her subordinates. Both traditional Thai and Western music and singing are employed. The set and lighting are designed in expressionist style to create frightful and woeful atmospheres particularly. Stylized costume is fashioned to suit the characters' roles; nevertheless, the colours of the costumes of certain characters are used in accordance with convention, such as green for Rama and golden-yellow for Lakshman.

\section{Nonthuk}

Nonthuk was Pornrat Damrhung's short experimental piece of performance in collaboration with two actors, Phichet Klunchuen and Dangkamol $\mathrm{Na}$ Pombejara. The performance was first staged at Chulalongkorn University in Bangkok and at the Inroads/Asia Conference at the University of California in August 1997, and again in January 1998 at Chulalongkorn University. In this production, Pornrat adapted the episode of Nonthuk, which was well-known in King Rama I's Ramakian as the origin of the story of Rama and Thotsakan.

According to the story, Shiva blesses his demon attendant, Nonthuk (Nandaka), a boon that enables him to transform his index finger into a diamond and destroy anyone at whom he points his finger. Since he is always mistreated by gods and goddesses, he takes this opportunity to take revenge and begins to misuse his power. Vishnu then assumes the responsibility for overpowering Nonthuk. Accordingly, the god transforms himself into a charming lady and seduces
Nonthuk to dance in imitation of her dancing. In one dance movement, Nonthuk happens to points his diamond finger towards his leg. He is eventually killed by the god and reborn as a demon with ten faces and twenty arms, called Thotsakan, whilst Vishnu swears that he will be reborn as a human called Rama who will again defeat the demon.

In experimenting with the production of Nonthuk, Pornrat presented the performance in the form of movement theatre, that is to say, only dance movements were used. The performance was played by only two actors - one (actor 1) as Nonthuk, and another (actor 2) as a god, Shiva, a lady and Vishnu. In fact, the names of the characters are never addressed, for there was no dialogue in the performance. The audience, however, can recognize the story and characters from the title. The performance will be divided into sequences, as follows:

\section{Sequence 1}

The performance starts with the fighting between actor 1 and actor 2, who is portraying a god. Actor 1 seems to lose in the fight.

Sequence 2

Actor 2, who is playing Shiva, empowers actor 1 .

Sequence 3

Actor 1 can beat actor 2 (probably the same god as in sequence 1).

Sequence 4

Actor 2 gradually changes his dance style to female gestures, then seduces actor 1 with sexual movements.

Sequence 5

Actor 2 abruptly turns to male gestures, which represents Vishnu. He and actor 1 fight; actor 1 is killed.

Pornrat looked into the original text and retold the story with a new viewpoint. 
Instead of the original theme about dhamma and adhamma (good and evil), she focused on the relation of the imbalance of power between social classes as well as power abuse. For her, the story was about the conflict and misuse of power. In this regard, she managed to reinterpret the original theme in relation to current events in society. As often seen in newspaper and television news, the issue of power abuse, she discovered, remains in everyday life and in every society. Moreover, sex and women are usually exploited to undermine an opponent. In producing Nonthuk, Pornrat and her collaborators, therefore, sought to demonstrate the extent to which woman seduces man in such a way that sex can destroy man. (Personal interview with Pornrat Damrhung, 24 March 1998.)

Pornrat, in directing this production, sought to experiment with the performers' interaction with the theme. This allowed the performers to express their feelings and movements freely in accordance with the theme. She also minimized all elaborations of theatrical forms found in traditional and modern performance. (See also Pornrat 1999: 43-52) For example, there was neither set nor property. Only a black backdrop is used. Both performers were vests and loose trousers.

In Nonthuk, Pornrat combined the use of Western movement and traditional Thai dance. As her experimental research, she directed her two actors, each of whom practised in different theatrical schools - modern and traditional - to present the conflict of power by using different styles of movements. While actor 1 or the demon used modern movement, actor 2 danced in traditional style. This implied a confrontation between Western and Thai theatrical forms.

\section{Sahatsadecha}

Sahatsadecha is an experimental work by Phatravadi. She called the form of the production "imaginative Ramakian"

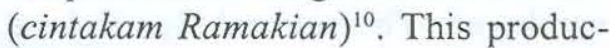
tion was first given in 1997 at her theatre and has been re-staged several times both inside and outside the country. It indicates Phatravadi's efforts to turn to traditional Thai performance in that she made use of khon (masked dance-drama) in conjunction with nang talung (Southern shadow puppet) to make the performance spectacular. ${ }^{11}$ In this experimental production, Phatravadi attempted to modernize traditional performance so as to attract a modern audience, particularly the younger generation.

Phatravadi, in selecting this production, was inspired by the khon performance of Sahatsadecha given by the Fine Arts Department (FAD) from which she drew worthy ideas for human life, as stated in the production's programme:

This episode of Ramakian contains a moral precept for human life. Lust and passion are allures which lead to disaster. The eyes, a window for a beautiful world, are an auspicious thing of life. But if one's mind has no morals, the eyes can turn inauspicious since they see only evil things. No matter how many eyes, ears, or hands one has, the important thing is whether happiness is in one's mind. If the mind is unhappy, it can bring

${ }^{10}$ Sahatsadecha (Programme), 1997.

${ }^{11}$ In fact, it is believed that khon has its origin in nang yai (large shadow puppet). Its evolution shows that khon was also performed together with nang yai; such combination of nang and khon is called nang tit tua khon (see Dhanit 1991: 28-35). 
disaster to relatives, friends, and even oneself. ${ }^{12}$

Phatravadi then began to study King Rama II's Ramakian and experimented with the presentation of the story in the form of khon. In this production, she mainly employed the dancers from $F A D$, together with some members of the Phatravadi theatre. She also had some leading master-dancers and experts of FAD and the Dramatic Arts College as consultants in traditional performance. The production was directed by Junlachat Aranyanak, a leading dancer of FAD, and Manop Micamrat, a prominent dancer of the Phatravadi theatre who had previously been trained in Western dance. Both of them also played roles in the performance. Phatravadi herself rewrote the script.

The script is based on King Rama II's Ramakian $^{13}$ and the script of the FAD's production. The episode of Sahatsadecha deals with the war between Sahatsadecha, a friend of Thotsakan, and Phra Ram's army. In writing the script, Phatravadi divided the story into ten scenes, as follows:

\section{Scene 1}

Phra Lak, Phra Ram's younger brother, disrupted a supernatural ritual of Intho'rachit, a son of Thotsakan. As a result, Intho'rachit was wounded by an arrow.

\section{Scene 2}

Montho, Intho'rachit's mother whose magic milk could cure the wound, allowed her son to drink milk from her breast. Though feeling embarrassed, Intho'rachit had to follow her suggestion. Montho suggested that Thotsakan should return Sida to Phra Ram to end

\footnotetext{
${ }^{12}$ Sahatsadecha (Programme), 1997.
}

the war, but he refused. Intho'rachit then was sent into battle again, despite realizing that this battle would be the end of his life.

Scene 3

Intho'rachit was killed by Phra Lak. Thotsakan therefore sent his other ten sons to fight, and they all died in the battle as well. Munphalam, Thotsakan's friend, and his brother, Sahatsadecha, who has one-thousand faces and two-thousand arms, moved the army to help Thotsakan fight Phra Ram's troop.

Scene 4

Sahatsadecha was annoyed with Montho who was crying due to her son's death and did not salute him. As he was displeased, he commanded his army to retreat. Montho was eventually forced to pay respect to Sahatsadecha - which satisfied him and thus made him return to assist in the fighting.

Scene 5

At the reception, Sahatsadecha and his army were drunk. After that, he moved his army to the battlefield.

\section{Scene 6}

Thotsakan's chariot was struck by a thunderbolt. Sahatsadecha then told him to return to Lo'nkka, Thotsakan's city. At the battlefield, Phra Lak's soldiers ran away as they were frightened by Sahatsadecha's enormous figure. Seeing this, Sahatsadecha then left the battlefield and let Munphalam fight Phra Lak.

Scene 7

Phra Lak was wounded by Munphalam's spear. However, Hanuman managed to save Phra Lak. In return, Phra Lak killed Munphalam with the spear.

\footnotetext{
${ }^{13}$ King Rama II rewrote the story of Ramakian from the episode of Hanuman presenting the ring to Sida to that of Thotsakan's death and from the episode of killing Sida to that of the remarriage of Rama and Sida (see King Rama II, 1956).
} 
Scene 8

Phra Ram consulted Phiphek, a brother of Thotsakan who became Phra Ram's assistant, about Sahatsadecha. After Phra Ram learned about Sahatsadecha's magic club, whose ends were able to kill or restore anyone to life when pointed at them, he commanded Hanuman to find a way to defeat Sahatsadecha.

Scene 9

Hanuman transformed himself into a small monkey. He tricked Sahatsadecha into giving him the magic weapon by pretending to be Sahatsadecha's subordinate.

Scene 10

Hanuman destroyed the magic club. Sahatsadecha was finally captured by Hanuman and was ridiculed by Phra Ram's monkey soldiers.

The performance ended with the tableau of Hanuman killing Sahatsadecha with his trident, and all main characters came out for a finale dance in which the lyric concluded the theme of the story, that is, intelligence is more important than power:

The story gives the idea That wisdom is very impor tant.

Although having supreme power,

It could turn helpless if one's mind is wicked.

Let's see Sahatsadecha,

Who has the greatest magic weapon,

Yet he was defeated by the little monkey

Just because of foolishness.

(Sahatsadecha: scene 10)

${ }_{14}$ Telephone interview with Phatravadi Mejudhon, 20 March 2001. In fact, this sequence does not appear in any versions of
In King Rama II's text, there existed no incident of Sahatsadecha's irritation at Montho. Scene 4, which Phatravadi took from the FAD's script $t^{14}$, was inserted to depict Sahatsadecha's temperamental, arrogant, demanding and irrational nature, as seen from the narrating dialogues (bot ceraca) between Sahatsadecha (S) and Munphalam (M):

Narrator for S:

As Sahatsadecha sees Thotsakan salute him, he is very pleased. But when his twothousand ears hear a sob, he finds a crying lady not saluting him. He is utterly furious, and thus stamps his foot as well as asking his brother who the lady behind Thotsakan is and what her name is.

Narrator for M:

Your majesty, that lady is called Montho, who is a dignified heavenly lady (saw sawan).

Narrator for S:

Oh! I see. The pretty Montho, the jet-set lady (saw hai-so)! She is the high-class angel. She did not salute (wai) me because she was afraid that her hands would be worn out. Seeing her husband bowing to me, she thought that it was disgraceful. This makes her burst into tears. And she does not care that I also lose my dignity. I was kind enough to carry my faces and grey hair (baek na pha hua $n g o$ 'k) here. Never mind! I think I must go back because she does not respect me.

Ramakian. The insertion of Sahatsadecha's displeasure at Montho is found only in the FAD's script written by Seri Wangnaitham, a former Director of the Music and Drama Division. See Sujit Wongthet 1998: 89-98. 
Sahatsadecha is getting angry, so he commands his army to return to Pangtan City.

(Sahatsadecha: scene 4)

The insertion of this scene highlights the negative portrayal of this character. In addition, the last two scenes demonstrate that Sahatsadecha is unintelligent as he is easily deceived, even if he has one-thousand faces, two-thousand arms and a magic weapon. His catastrophe resulted from his evil mind in that he offered his hand in a wrong way by helping Thotsakan, who abducted Phra Ram's wife. Phatravadi's reworking of this episode indicates her effort to convey the message of the traditional literary work to a modern audience. Such effort help to relate the value of the past to a modern audience. In other words, it proves the value of the work in a modern social context.

To clarify Phatravadi's innovation of khon in this production, it is helpful to describe some characteristics of traditional khon performance.

Traditionally, the main elements of $k h o n$ performance, which differentiate khon from other types of traditional dancedrama, are kham phak (a narration recited or sung in poetic verse) and bot ceraca (poetic dialogue). While the kham phak is composed in the form of $k a p$, a sort of ancient verse form, the ceraca is written in rai, another pattern of ancient verse. The kham phak is used for telling the story as well as showing a character's action and

\footnotetext{
${ }^{15}$. The kham phak can be can be categorized into six types: phak mu'ang (used when a character stays in palace or pavilion), phakrot (used for describing the beauty of vehicles), phak oh (used when a character expresses sadness), phak chom dong (used
}

feeling, and sometimes for describing the beauty of nature or vehicles such as a chariot, elephant, or horse. ${ }^{15}$ The bot ceraca functions not only as the dialogue,but also as the narration of a character's action and feeling. In this sense, the first-person pronoun together with a character's name (in the third person) are sometimes contained in one dialogue. (See the dialogues between Sahatsadecha and Munphalam above.) The kham phak and bot ceraca are sung and spoken by singer-narrators, usually two separate persons. However, after khon was influenced by the lakho'n convention, singing has been also used in the khon performance to such an extent that the kham phak is now rarely found.

Like other kinds of traditional dancedrama, there are two types of song in the khon performance: phleng na phat and phleng ro'ng. The phleng na phat is a category of music without lyrics used when a character expresses certain actions and feelings, such as making a journey, making love, moving troops, showing magic power, crying, and so on. The selection of phleng na phat is considered from the particular function of music together with a character's role and status. For example, kraw no' $k$ is used when the monkey's troop is moving, whereas kraw nai is used for the moving of a demon's troop; bat sakuni is used with a particular character such as Phra Ram and Phra Lak when they make a journey, chup is used for the journey of maids. The phleng ro'ng is a range of music used for telling the storyas well as a character's action and feeling.

for describing the beauty of nature), phak banyai (used for telling the background of something) and phak bettalet (used for describing miscellaneous things or events). See Dhanit Yupho 1991: 104-107. 
The melody is taken from the traditional repertoire. According to Montri Tramot, a leading traditional musician, the selection of melody used in traditional dancedrama is subject to the emotion of the lyrics or story, the theatrical genre, and the character's status. (Montri 1993: 54-59) In traditional dance-drama, it is unconventional to use repeated melody, except for a few melodies used for moving the pace of performance, e.g. phleng rai.

In khon performance, costume and mask are an element that enables the audience to identify a character's role. According to convention ${ }^{16}$, each character uses a specific colour of costume and mask. For example, Phra Ram's costume is green, while Phra Lak wears a golden costume. In the convention of dressing in traditional dance-drama, the colours of upper and lower garment should be in a contrasting shade such as Phra Ram wearing green embroidered tight-fitting top and close-fitting, kneelength trunks with red brocade worn over the trunks. Traditionally, almost every character wears a mask; yet from the reign of King Vajiravudh onwards, only characters in monkey and demon roles wear masks. (Kukrit 1983: 15 and 20) The feature of each mask is different: crowned or uncrowned, finial of crown, colour, eyes, mouth, fangs, etc.

According to the convention, the khon performance begins with the non-lyric music called phleng wa which functions as a sign that the performance is about to start and is a music used to enable the dancers to come into the scene. (Dhanit 1991: 140) Major characters in dance-drama customarily enter the

${ }^{16}$ See the colour and the characteristics of mask of the characters in Ramakian in Praphan, 1971. scene from stage right, which is on the left hand side of audience, and exit at the other side, with the exception of fighting scenes in which the characters can enter from both sides. With regard to emotional expressions, dancers do not show any facial expression because they wear masks; the audience can realize the characters' feelings from lyrics, dialogue, phleng na phat, and dance gestures. Even when certain characters in some roles no longer wear masks, such convention is still practised. In some senses, this is also due to the custom of court dance-drama, where the dancers should not express their emotions as much as in folk dance-drama.

In adopting the theatrical form of khon, Phatravadi (videotape, 1998) pointed out that contemporary performance should not reject the traditional form, yet such traditional wisdom (phum panya banphaburut, lit. ancestors' wisdom) should be used in combination with modern elements or technologies. In this production, she adjusted some characteristics of khon performance to quicken the pace of performance, and employed modern theatrical elements to make the performance more attractive and spectacular. However, dance movement, which was an essential part of the performance, was maintained in accordance with the convention of Thai dance.

At the beginning of the performance, the traditional music of phleng wa was discarded. Instead, the main characters, namely, Montho, Intho'rachit, Thotsakan, Phra Lak, Hanuman, and Sahatsadecha respectively, were introduced by performers dancing the ram na phat, a type of traditional dance accompanied by the phleng na phat, in association with the manipulation of each character's shadow puppet on the 
screen. For example, Montho' danced in phleng cha whose melody is soft and graceful, Intho'rachit in phleng rua which is usually used when a character shows magical power, Hanuman in kraw no' $k$ which is the music for the movment of a troop of monkeys. Although the employment of ram na phat here conformed to the convention of using the phleng na phat to fit into the characters' role and status, it was unlikely to be able to introduce the characters' names to an audience unfamiliar with the story and khon performance. Rather, the introduction scene merely enabled the audience to recognize the characters and their puppets. Such introduction was not necessary for an audience in the old days since they would recognize characters from the masks, costumes, and lyrics. In this introduction scene, Phatravadi made use of lighting and the side legs, which basically hide the wings of the stage from the audience's view, to create the shadow of characters before they entered the scene. The introduction scene, thus, was inserted to make the performance spectacular.

Singing, dialogue narrating (ceraca), and dancing were employed to convey the story; yet ceraca was used to a larger degree than music in order to quicken the pace of the performance. The ceraca in this production was found in rai and klo'n verse forms; these klo'n poems were quoted from King Rama II's version. It is interesting to note that the kham phak was completely discarded to avoid prolonging the performance.

Generally, the phleng na phat and phleng ro'ng were employed to describe the characters' actions and emotions; a few phleng ro'ng also functioned as dialogue. In the song where monkey soldiers mock Sahatsadecha when he is caught, the interjection hui $h a$ (a word giving a meaning of laughing) was inserted at the end of each line to emphasize a sense of ridiculing. Such an insertion of a refrain was borrowed from the tradition of folk singing, often found in lakho'n no'k. In contrast to the convention of using traditional melodies in phleng ro'ng, the Thale Ba (lit. mad sea) melody was found twice in the songs where Sahatsadecha is angry after learning about Thotsakan losing the battle and where Sahatsadecha is mocked by monkeys. This illustrates that the selection of traditional melodies in this production was mainly based on the emotion of song rather than on the convention.

The use of shadow puppets was influenced by nang yai (an ancient-style large shadow puppet) in terms of the manipulator's movement and nang talung in terms of the manipulation and the puppet's size. Unlike traditional nang talung and nang yai, the shadow puppet was made from carved paper instead of leather. The patterns and designs of the puppets were taken from traditional painting. Although the puppets in this production were devised to show the movements of head, arm, and mouth close to that of nang talung, the technique was borrowed from Japanese puppetry, by using elastic bands to control movements such as nodding. ${ }^{17}$ In the scene in which Intho'rachit is killed, moreover, the puppet of Intho'rachit was devised so as to enable separation of its head from its body to depict Intho'rachit's

${ }^{17}$ Having seen a Japanese puppet show for children, Phatravadi then had the idea to make use of the movement of puppetswhich she found interesting for younger generations. (Telephone interview with Phatravadi Mejudhon, 20 March 2001). 
decapitation. This technique was also taken from Japanese puppetry. The employment of shadow puppets in this scene indicates a subtle technique in avoiding showing the death scene by a dancer on stage - which was forbidden in traditional theatrical convention. As the performance made use of shadow puppetry in alternation with dancers, the story could develop rapidly. The use of shadow puppetry also made the performance more attractive due to the variety of theatrical forms.

Phatravadi contrived to have the characters enter the scene from both sides, mostly from stage left (on the right-hand side of audience) - which did not conform to convention. Blocking, which is the way to move actors on the stage area, was executed in modern style to enhance dramatic effect. The nonmasked characters, Montho in particular, revealed their facial and emotional expression to some extent. Such characters' expression made the performance more realistic and attractive.

Special effects, such as slides, sounds and lights, were used to make the performance impressive. Slides were used to clarify the visual aspects of performance, such as showing Sahatsadecha's innumerable eyes - impossible to find in a traditional mask. In some cases, they were also used to suggest the scenery, e.g., the throne hall. Sound effects were employed to create the atmosphere of the performance, e.g., rain falling and the sound of burning. The techniques used in this performance were rather simple, such as pouring rice into a bottle to produce a rain-fall sound and using a intereaction between mirror, water, and lighting to create flame. Modern lighting technique was specially designed for the shadow puppetry and was used to enhance the traditional performance, to make it more spectacular.

To achieve artistic quality, Phatravadi employed foreign theatre practitioners, such as Katsura Kan as lighting designer, Noriko Tomatani as sound designer, Zen-San as a trainer for creating the puppets, and Anthony Hodgson as special effect designer. Like her previous productions, her collaboration with foreign theatre practitioners showed the adoption of foreign techniques, either Oriental or Western, in Thai theatrical production so as to gain an audience's attention. Such direct involvement of foreign theatre practitioners in this production further reflected Phatravadi's attempts to employ foreign techniques to modernize traditional Thai theatre.

After thirty-five shows at the Phatravadi Theatre, in 1998, the production of Sahatsadecha was selected to join the Project "Ruam Phalang Han So'ng" (Join Forces to Reduce the Use of Energy by Half), the campaign to promote energy saving, organized by the National Energy Policy Office. The project was to make people conscious about using energy effectively and to promote energy conservation through performance in order to demonstrate that every activity can reduce the use of resources and energy without deteriorating the artistic quality of the work. The production, re-staged across the country in forty shows, was then known as Khon Han So'ng. (The phrase han so'ng literally means "divided by two".)

When staged at the Phatravadi Theatre, the production used the traditional yu'n khru'ang outfits, i.e., elaborately embroidered tight-fitting clothes with headdress or mask, according to con- 
vention. The costumes in the performances for this project were adjusted to serve the project's objective. Even though it was based on the $y u$ 'n khru'ang costume, the materials used were adapted to reduce expense and to make the costumes light and washable. In so doing, satin was replaced by local hand-made fabric, and the costume was embroidered with glittering beads instead of sequin and tinsel in order to lighten the weight. The patterns of the costumes were taken from those of traditional costumes in the reigns of King Rama II and King Chulalongkorn. Phatravadi (videotape, 1998) believed that when the costume became lighter, the performers could dance more easily and powerfully -which would attract a younger audience. Certain characters, such as Munphalam, and monkey and ogre soldiers, wore only a lower garment in traditional style with bare chests, yet their bodies were painted in accordance with the traditional colour of the characters. However, the use of colour, which was able to identify a character, did not follow the convention of khon performance, particularly the colour of Montho's costume. According to convention, Montho should wear a white shawl, and the colour of her lower garment should be in a contrasting shade. In this production, both the upper and lower garments of her costume were in shades of blue. Regardless of the convention, the use of colour for this character was motivated by artistic principles, and the costume became more colourful than that dictated by tradition.

In order to serve the objective of the

${ }^{18}$ Phatravadi claimed that the costumes for this project were four times cheaper than traditional costumes. (Telephone interview with Phatravadi Mejudhon, 20 March 2001). project in saving energy, Phatravadi deliberately reduced the expense and the use of labour and electricity. Under this project, labour and electricity were decreased to show worthwhile and effective ways in using energy. The performance used fewer dancers and singers; each performer needed to be involved in many parts of the production, such as playing a character's role and manipulating a shadow puppet. The singer also functioned as the singernarrator - which was different from the traditional khon performance, where singer and singer-narrator are different people. The singers and the musicians also produced sound effects. The lighting, which had required more than two hundred spotlights in the 1997 production, was cut down to twenty five spotlights by illuminating only the area where the characters were positioned. In addition, newly created costumes helped to further reduce the costs. ${ }^{18}$ The reduction of expense, labour, and electricity reflects not only the effective use of energy to retain the artistic quality, but also the use of theatre to serve official policy. Apart from this project, Sahatsadecha was also re-stage, by invitation, at the Biennale de la Danse Festival in Lyon in 2000.

\section{Conclusion}

The circumstance of a cultural crisis seemingly provokes the imaginary sense of Thai-ness, which has been deeply instilled in people's consciousness. However, Thai-ness today is not able to resist 'otherness' 19 under the conditions of

\footnotetext{
${ }^{19}$ According to Thongchai (1994: 3-6), the existence of otherness, un-Thai-ness, is as necessary as the positive definition of Thainess in which Thai-ness is clearly defined Yet in reality, it is difficult to define clearly; the domain of what is not Thai or un-Thai is therefore identified from time to time, which Thongchai called 'negative identification'.
} 
cultural globalization; on the contrary, it is necessary to select whatever 'foreign' or 'un-Thai' element of external culture is deemed compatible and workable for the society. Such selection is discernible from the reproductions of Ramakian in the 1990 s.

As a national literary heritage, Ramakian is inevitably utilized to deal with the problem of cultural crisis, as it was in the past. However, its presentation, either of content or form, must be adjusted to fit contemporary society. Obviously, these theatre practitioners seek to retell the story of Ramakian in a way that comes closer to the audience. The combination of Thai and Western elements in modern theatre also reflects the modification of Thai culture to fit into cultural globalization. In the "National Cultural Policy and the Guidelines for the Preservation, Promotion, and Development of Culture' (1986), culture is a changeable 'thing'. The 'old' culture might be replaced by new culture if innovations can solve social problems and respond to social demands more effectively. Thereby, the traditional theatrical form, which is no longer relevant to the everyday life of people today, is merely an 'old' sign preserved as the cultural heritage of the nation, while making use of modern form, juxtaposing traditional and modern elements, and adapting minor elements in traditional theatre are acceptably employed in the hope of bringing the modern audience back to their cultural roots.

\section{References}

Bechstedt, Hans-Dieter. 1993. "Identity and Authority in Thailand". In $\mathrm{Na}$ tional Identity and its Deender: Thailand, 1939-1989, ed. by Craig
J. Reynolds, pp. 293-321. Chiang Mai: Silkworn Books.

Dhanit Yupho. 1991. Khon. Published on the occasion of H.R.H. Princess Maha Chakri Sirindhorn's 36th birthday anniversary and seminar on Thai dance and drama, Bangkok: Thai Khadi Research Institute, Thammasat University.

Ekkawit Na Thalang. 1989. "Su'p Tho't lae Prap Pron Watthanatham hai Som Samai" (The Continuation and Adjustment of Culture to Fit into the Time), Sinlapa Watthanatham (Art and Culture) 10: 7: 106-114.

Inthrayut (Atsani Phonlacan). 1975. Kho' Khit Cak Wannakhadi (Insight into Literature).Bangkok: Sunklang Nakrian haeng Prathet Thai

Kittisak Kerdarunsuksri. 2001. The Transposition of Traditional Thai Literature into Modern Stage Drama: The Current Development of Thai Theatre. Unpublished Ph.D. Thesis, University of London. 2002. "Malai Mongkhon: A Case of Postmodern Thai Theatre". Manusya: Journal of Humanities 5: 1:50-66.

Kukrit Pramoj, Mo'm Ratchawong. 1983. Nattasin Thai (Thai Dance and Drama), Bangkok: Thai Watthanaphanit.

Mattani Mojdara Rutnin. 1996a. Dance, Drama, and Theatre in Thailand: The Process of Development and Modernization. Chiang Mai: Silkworm Books. . 1996b. Rama - Sida. (Unpublished script and videotape.)

Montri Tramot. 1993. "Lak nai Kan Bancu Phleng Prako'p Kan Sadaeng Nattasin" (Rules of Making Use of Melody in Dance and Drama). In Nattasin Thai (Thai Dance and Drama), ed. by Mo'm 
Luang Wanwipha Burutrattanaphan. Published on the celebration of H.R.H. Maha Chakri Sirindhorn's $36^{\text {th }}$ birthday anniversary and proceeding of seminar on Thai dance and drama, 14-15 March 1991, Bangkok: Thai Khadi Research Institute, Thammasat University, 1993, pp. 54-59.

National Culture Commission, Office of the, Ministry of Education. 1986. Nayobai Watthanatham haeng Chat lae Naewthang nai Kan Raksa Songsoem lae Phatthana Watthanatham Phutthasakkarat 2529 (The National Cultural Policy and the Guidelines for the Preservation, Promotion, and Development of Culture 1986). Bangkok: Khurusapha.

n.d. Kan Ronnarong Watthanatham Thai pho' so' 2537-2540 (The Campaign for Thai Culture 1994-1997). Bangkok: n.p.

Nithi Aiewsiwong. 1995. "So'ng Roi Pi kho'ng Kan Su'ksa Prawattisat Thai lae Thang Khang Na" (Two Hundred Years of Thai Historical Studies and its Future). In Krung Taek, Phra Cao Tak lae Prawattisat Thai (Broken City, King Taksin and Thai History). Bangkok: Matichon. Phatravadi Mejudhon. 1998. Personal interview. 3 June. . 1997. Sahatsadecha (Unpublished script and programme). 1998. Sahatsadecha (Videotape recorded at the performance for the Ruam Phalang Han So'ng Project). . 2001. Telephone interview. 20 March.

Pornrat Damrhung. 1997. Nonthuk (Videotape). 1998. Personal interview. 24 March. 1999. "Cultivating the Garden of
Theatre Culture: A New View on Traditional Theatre in Thailand". Manusya: Journal of Humanities. 2: 2: 27-60.

Praphan Sukhonthachat. 1971. Hua Khon (Masks of Khon), Bangkok: Siwapo'n.

Rama I, King (Phrabat Somdet Phra Phutthayodfa Chulalok). 1964. Ramakian. 11 vols. Bangkok: Khurusapha.

Rama II, King (Phrabat Somdet Phra Phutthaloetlanaphalai). 1956. Bot Lakho'n Ru'ang Ramakian (The Play of Ramakian). Bangkok: Sinlapa Bannakhan.

Reynolds, Craig J. (ed). National Identity and its Defenders: Thailand, 1939-1989. Chiang Mai: Silkworm Books, 1993.

Sujit Wongthet, ed. 1998. Khot Wong Thotsakan (Thotsakan's Ancestry). Bangkok: Matichon.

Sulak Sivaraksa. 1993. The Crisis of Siamese Identity. In National Identity and its Defender: Thailand, 1939-1989. ed. by Craig J. Reynolds, pp. 41-58. Chiang Mai: Silkworm Books.

Thongchai Winichakul. 1994. Siam Mapped: A History of the Geobody of a Nation. Chiang Mai: Silkworm books.

Vajiravudh, King (Phrabat Somdet Phra Mongkutklao Cao Yu Hua). 1959. Ramakian Bot Ro'ng lae Bot Phak. Bangkok: Chulalongkorn University.

- 1960. Bo' Koet haeng Ramakian. Bangkok: Kurusapha.

Vella, Walter F. Chaiyo! King Vajiravudh and the Development of Thai Nationalism. USA.: The University Press of Hawaii.

Vichitr Vadakarn, Luang. 1970. Maha Burut (The Great Men). $7^{\text {th }}$ ed. Bangkok: Soemwit Bannakhan. 
Wanwipha Burutrattanaphan, Mo'm Luang, ed. 1993. Nattasin Thai (Thai Dance and Drama), Published on the celebration of H.R.H. Maha Chakri Sirindhorn's $36^{\text {th }}$ birthday anniversary and proceeding of seminar on Thai dance and drama, 14-15 March 1991, Bangkok: Thai Khadi Research Institute, Thammasat University.
Wyatt, David K. 1996. "The 'Subtle Revolution' of King Rama I of Siam". In Studies in Thai History. Chiang Mai: Silkworm 